\title{
On the avoidability of breast cancer in industrialized societies: older mean age at first birth as an indicator of excess breast cancer risk
}

\author{
Isabelle Soerjomataram • Eero Pukkala • \\ Hermann Brenner · Jan Willem W. Coebergh
}

Received: 25 September 2007/ Accepted: 25 September 2007/Published online: 12 October 2007

(C) Springer Science+Business Media, LLC. 2007

\begin{abstract}
Background Breast cancer incidence continuous to increase. We examined at population level the association between the relative excess risk of breast cancer and previous age of mother at first birth. Method Incidence of breast cancer in 34 industrialized countries was obtained from the GLOBOCAN 2002 and SEER databases. Data on age of mother at first birth was collected through national statistics offices. National relative excess risk (RER) was calculated by subtracting the lowest age-specific incidence rate from the rate in each population, and dividing the difference by the latter. Results The national RER in 2002 correlated closely with a higher average age at first birth in 1972, 1982, 1992 and also 2002, Pearson correlation [r] being $0.83,0.79,0.72$ and 0.61 , respectively; $P<0.0001$. RER of breast cancer in 2002 for those aged 15-44 years correlated closely with the mean age at first birth in 1982 and 1992 ( $r: 0.81$ and $0.75 ; P<0.0001$ ), whereas RER for those aged 45-54 years correlated strongly with age at first birth in 1972 and 1982 ( $r: 0.81$ and $0.76 ; P<0.0001)$, and for those aged 55-64 years with age at first birth in 1972
\end{abstract}

I. Soerjomataram $(\bowtie) \cdot$ J. W. W. Coebergh

Department of Public Health, Erasmus MC, P.O. Box 2040, 3000

CA Rotterdam, The Netherlands

e-mail: i.soerjomataram@erasmusmc.nl

I. Soerjomataram · J. W. W. Coebergh

Comprehensive Cancer Centre South, P.O. Box 231, 5600 AE

Eindhoven, The Netherlands

E. Pukkala

Institute for Statistical and Epidemiological Cancer Research, Finnish Cancer Registry, Helsinki, Finland

H. Brenner

Division of Clinical Epidemiology and Aging Research, German

Cancer Research Center, Heidelberg, Germany
( $r: 0.77 ; P<0.0001)$. Conclusions The rising age at first childbirth of mothers has been followed by marked increases in breast cancer incidence. Later age at first birth seems to characterize secular diffusion of 'modern' lifestyles with a potentially large impact on increased breast cancer risk, and hence should be accompanied by greater opportunities for prevention through modifiable risk factors.

Keywords Breast Neoplasms · Correlation studies · International perspective $\cdot$ Reproductive behaviour . Risk

\section{Introduction}

Global trends in breast cancer incidence have been attributed to various factors including reproductive history and hormonal factors, female body composition and nutritional factors, also alcohol consumption [1-3]. Higher socioeconomic status has also been associated with a higher risk of breast cancer [4]. Furthermore, increased use of mammography has increased the detection rate leading to a higher observed breast cancer incidence [5]. Reproductiverelated factors including age at birth of first child and number of children has been suggested as one of the major determinants of breast cancer incidence [2], and has been attributed to $28 \%$ of its incidence [6]. Women who had their first birth at age 35 or older exhibit a $60 \%$ higher risk of breast cancer than women who had their first child at age 20-21 [7]. There are large differences between countries in the age of the mother at first birth [8], as well as in the incidence of breast cancer [9]. Recent and historical data on national fertility patterns are available and comparable for most western populations. However the role of 
mother's age at first birth in the past, marking current breast cancer risk has not yet been examined. Thus, we assessed the association between age at first birth and the excess risk of breast cancer a few decades later using data from 34 industrialized countries.

\section{Methods}

\section{Materials}

We performed this study within the framework of the European collaborative project Eurocadet, which estimates the future potential of cancer prevention based on recent trend in cancer incidence and its related risk factors [10]. Incidence data was obtained from GLOBOCAN 2002 [11] and the SEER database for white non-Hispanic Americans [12]. We included European countries (Austria, Belgium, Bulgaria, Croatia, Czech Republic, Denmark, Estonia, Finland, France, Germany, Greece, Hungary, Ireland, Italy, Latvia, Lithuania, Former Yugoslavic Republic of Macedonia, The Netherlands, Norway, Poland, Portugal, Romania, Serbia and Montenegro, Slovakia, Slovenia, Spain, Sweden, Switzerland and United Kingdom) as well as Australia, Canada, Israel, New Zealand and the USA. In GLOBOCAN 2002 incidence rates were estimated based on the best available data from national or regional cancer registries. Methods of estimation and correction for suspected under-recording have been described elsewhere [11]. We included only countries with more than 1 million inhabitants. Data on mother's average age at first birth in 1972, 1982, 1992 and 2002 or approximately the same period were retrieved from EUROSTAT [8] or National Statistics Institutes for non-European countries (Table 1). In the United States, we only included data of non-Hispanic whites.

\section{Statistical analysis}

Incidence rates for breast cancer were calculated by 5 -year age groups and age-adjusted (world standard population) for truncated age categories $(15-44,45-54,55-64$ and $65+)$. Excess incidence was calculated by subtracting the lowest rate age-specific observed in the selected countries from the respective national rate. Incidence rate was lowest in Czech Republic for age group 15-44, in Lithuania for age groups 45-54 and 65+, and in Latvia for age group 5564. Absolute numbers of excess cases were calculated by multiplying the excess incidence rates by the size of the population of the country of interest in the same period and age group [13]. Relative excess risk (RER) was calculated as the ratio of excess incidence and observed incidence in a country. We used the Pearson correlation coefficient to quantify the relationship between national RER and current as well as past average age of the mother at first birth. We also examined the correlation of age at first childbirth in 1972 and 1982, and 1992 with RER for those aged 45-54 and 15-44 years, respectively. We assumed that most women of 45-54 years in 2002 had their first childbirth between the 1970s and the 1980s. The age group 15-44 years mostly comprised breast cancer cases older than 35 years, who typically had their first childbirth in between the 1980s and the 1990s. In addition, we correlated RER for those aged 55-64 years in 2002 to average age at first child in 1972. These women most likely had their first child between 1965 and 1975. Correlation analysis was performed only with the year 1972, because data of the 60 s were scarce. In order to take the large variation of population sizes of the included countries into account, correlation coefficients were weighted by population sizes in the respective age groups.

\section{Results}

The highest overall age-adjusted relative excess risk of breast cancer was found for Belgium, France, New Zealand and the Netherlands $(59 \%, 57 \%, 55 \%$ and $54 \%$ ), whereas the lowest was in Romania and Czech Republic (9\% and $14 \%)$ (Table 1). Incidence rates for two age groups (45-54 and $65+$ years) were lowest in Lithuania, which explains the low RER for this population (1\%). In countries with the highest RER in 2002, the average age at first birth was 24-25 years in 1972, 25-26 years in 1982, 27-28 years in 1992 and 28-29 years in 2002. In contrast, mothers in countries with the lowest RER in 2002 had their first child at 23 years in 1972, 22-24 years both in 1982 and 1992 and 24-26 years in 2002 (Table 1). Figure 1 illustrates the correlations between RER in 2002 for 15-44 years, 45-54 years and 55-64 years with mean age at first child in 1972, 1982 and 1992. Mean age at first childbirth in 1982 and 1992 correlated closely with RER of breast cancer in 2002 for those aged 15 to 44 years $(r: 0.81$ and $0.75 ; P$-value $<0.0001)$. Among 45 to 54 year old breast cancer cases, the corresponding correlations were 0.81 for 1972 , and 0.76 for 1982 . The correlation for average age at birth of first child in 1972 and RER for those aged 55 to 64 in 2002 was 0.77 ( $P$-value $<0.0001)$. Finally, we found a decreasing magnitude of the correlation between RER in 2002 for $15+$ years with increasing calendar year of mean age at first child (figure not shown); Pearson correlation coefficients $(r)$ were 0.83 for 1972, 0.79 for 1982, 0.72 for 1992 and 0.61 for 2002 ( $P$-value $<0.0001)$. 
Table 1 Fertility pattern and relative excess risk of breast cancer by period

\begin{tabular}{|c|c|c|c|c|c|c|c|c|}
\hline \multirow[t]{2}{*}{ Countries } & \multicolumn{4}{|c|}{ Average age at first birth (years) } & \multicolumn{4}{|c|}{ Relative excess risk in $2002(\%)$} \\
\hline & 1972 & 1982 & 1992 & 2002 & All ages & $\begin{array}{l}\text { Age group } \\
15-44\end{array}$ & $\begin{array}{l}\text { Age group } \\
45-54\end{array}$ & $\begin{array}{l}\text { Age group } \\
55-64\end{array}$ \\
\hline Australia $^{a}$ & n.a. & 25.5 & 28.0 & 30.2 & 49.9 & 46.9 & 50.4 & 59.5 \\
\hline Austria & n.a. & $24.1^{\mathrm{c}}$ & 25.0 & 27.4 & 45.9 & 47.0 & 36.7 & 48.9 \\
\hline Belgium & 24.3 & 24.9 & 26.7 & $27.6^{\mathrm{i}}$ & 59.1 & 59.8 & 58.9 & 59.3 \\
\hline Bulgaria & 22.1 & 21.9 & 21.9 & 23.9 & 21.1 & 25.2 & 11.7 & 18.3 \\
\hline Canada & n.a. & 24.9 & 26.0 & 27.7 & 48.0 & 43.7 & 47.8 & 57.5 \\
\hline Croatia & n.a. & $23.5^{\mathrm{d}}$ & $24.7^{\mathrm{g}}$ & 25.9 & 37.5 & 37.1 & 34.7 & 40.5 \\
\hline Czech Republic & 22.6 & 22.4 & 22.5 & 25.6 & 14.0 & ref & 27.6 & 37.4 \\
\hline Denmark & 24.0 & 25.0 & 26.9 & $28.5^{\mathrm{j}}$ & 48.8 & 43.2 & 51.3 & 63.0 \\
\hline Estonia & 23.9 & 23.3 & 22.8 & 24.6 & 19.4 & 19.2 & 21.5 & 17.8 \\
\hline Finland & 24.6 & 25.4 & 26.7 & 27.6 & 48.2 & 42.7 & 59.6 & 56.6 \\
\hline France & 24.3 & 25.3 & 27.4 & $27.9^{\mathrm{k}}$ & 57.4 & 56.7 & 58.8 & 61.2 \\
\hline Germany & 24.1 & 25.4 & 26.9 & 28.6 & 49.6 & 47.7 & 50.2 & 54.5 \\
\hline Greece & n.a. & 24.2 & 26.0 & 27.9 & 22.0 & 19.1 & 27.4 & 21.6 \\
\hline Hungary & 22.7 & 22.6 & 23.3 & 25.6 & 29.3 & 21.9 & 36.2 & 41.6 \\
\hline Ireland & 25.8 & 25.6 & 26.7 & 28.0 & 41.5 & 35.6 & 49.9 & 54.7 \\
\hline Italy & 24.9 & 25.3 & 27.3 & $28.6^{1}$ & 50.0 & 51.5 & 47.2 & 45.2 \\
\hline Israel & n.a. & n.a. & $24.4^{\mathrm{h}}$ & 25.8 & 46.5 & 38.1 & 55.5 & 62.9 \\
\hline Latvia & n.a. & 22.9 & 22.8 & 24.9 & 16.6 & 20.6 & 8.7 & ref \\
\hline Lithuania & n.a. & 24.2 & 23.1 & 24.3 & 0.9 & 1.4 & ref & 0.1 \\
\hline Macedonia & n.a. & na & 23.5 & 24.7 & 26.7 & 27.4 & 22.5 & 24.9 \\
\hline New Zealand & n.a. & 25.6 & 28.4 & 30.4 & 55.3 & 53.7 & 52.2 & 66.4 \\
\hline Norway & n.a. & $24.8^{\mathrm{e}}$ & 25.9 & 27.2 & 40.8 & 34.5 & 48.3 & 53.7 \\
\hline Poland & 23.0 & 23.4 & 23.4 & 25.0 & 17.5 & 12.0 & 30.4 & 22.7 \\
\hline Portugal & n.a. & 24.0 & 25.2 & 26.8 & 33.3 & 35.5 & 35.1 & 26.2 \\
\hline Romania & 22.5 & 22.5 & 22.6 & 24.1 & 9.2 & 5.4 & 18.5 & 14.2 \\
\hline Serbia and Montenegro & n.a. & $23.5^{\mathrm{f}}$ & 24.2 & 25.5 & 37.0 & 39.6 & 37.0 & 30.5 \\
\hline Slovakia & 22.7 & 22.7 & 22.6 & 24.7 & 17.1 & 15.1 & 18.2 & 13.7 \\
\hline Slovenia & 23.3 & 23.1 & 24.1 & 27.2 & 30.5 & 27.4 & 30.6 & 33.7 \\
\hline Spain & 22.5 & 25.4 & 27.5 & 29.2 & 25.1 & 25.4 & 28.4 & 23.3 \\
\hline Sweden & 26.0 & 25.6 & 26.7 & 28.3 & 47.6 & 41.3 & 51.8 & 64.6 \\
\hline Switzerland & 25.4 & 26.5 & 27.8 & 29.0 & 51.1 & 50.4 & 44.3 & 57.4 \\
\hline The Netherlands & 24.8 & 26.0 & 28.0 & 28.7 & 54.5 & 53.3 & 57.1 & 53.2 \\
\hline United Kingdom & 24.1 & 25.4 & 27.8 & 29.3 & 52.7 & 50.1 & 54.2 & 58.5 \\
\hline United States ${ }^{b}$ & n.a. & n.a. & 25.1 & 26.1 & 52.9 & 48.1 & 51.3 & 64.6 \\
\hline
\end{tabular}

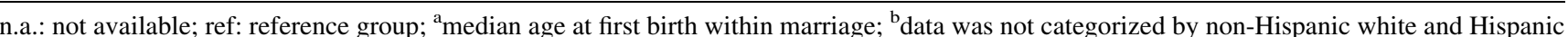
white before 1989; ${ }^{\mathrm{c}}$ data in $1984 ;{ }^{\mathrm{d}} 1983 ;{ }^{\mathrm{e}}$ median age at first birth within marriage in 1976-1980; ${ }^{\mathrm{f}}$ data in 1983 ; ${ }^{\mathrm{g}}$ data in 1993; ${ }^{\text {h}}$ data in 1994 ; ${ }^{\mathrm{i}}$ data in 1997 ; ${ }^{\mathrm{j}}$ data in 2001 ; ${ }^{\mathrm{d}}$ data in 2000 ; ${ }^{1}$ data in 1998

\section{Discussion}

We observed a strong correlation between the overall excess incidence of breast cancer in 2002 and the average age of the mother at first birth in 1972-2002. Both current and past average age at first childbirth were related with recent excess risk of breast cancer. The earliest period of exposure assessment correlated best with the current excess risk of breast cancer. For those aged about 40 at breast cancer diagnosis in 2002, mean age at first childbirth in 1982 and 1992 correlated closely with their excess risk. For those aged about 50 years at diagnosis, age at first birth in 1972 and in 1982 correlated with their current excess risk. Finally, for those aged about 60 years at diagnosis, age at first birth in 1972 strongly correlated with their current excess risk.

We determined excess breast cancer incidence as the difference between national incidence rates and the lowest 


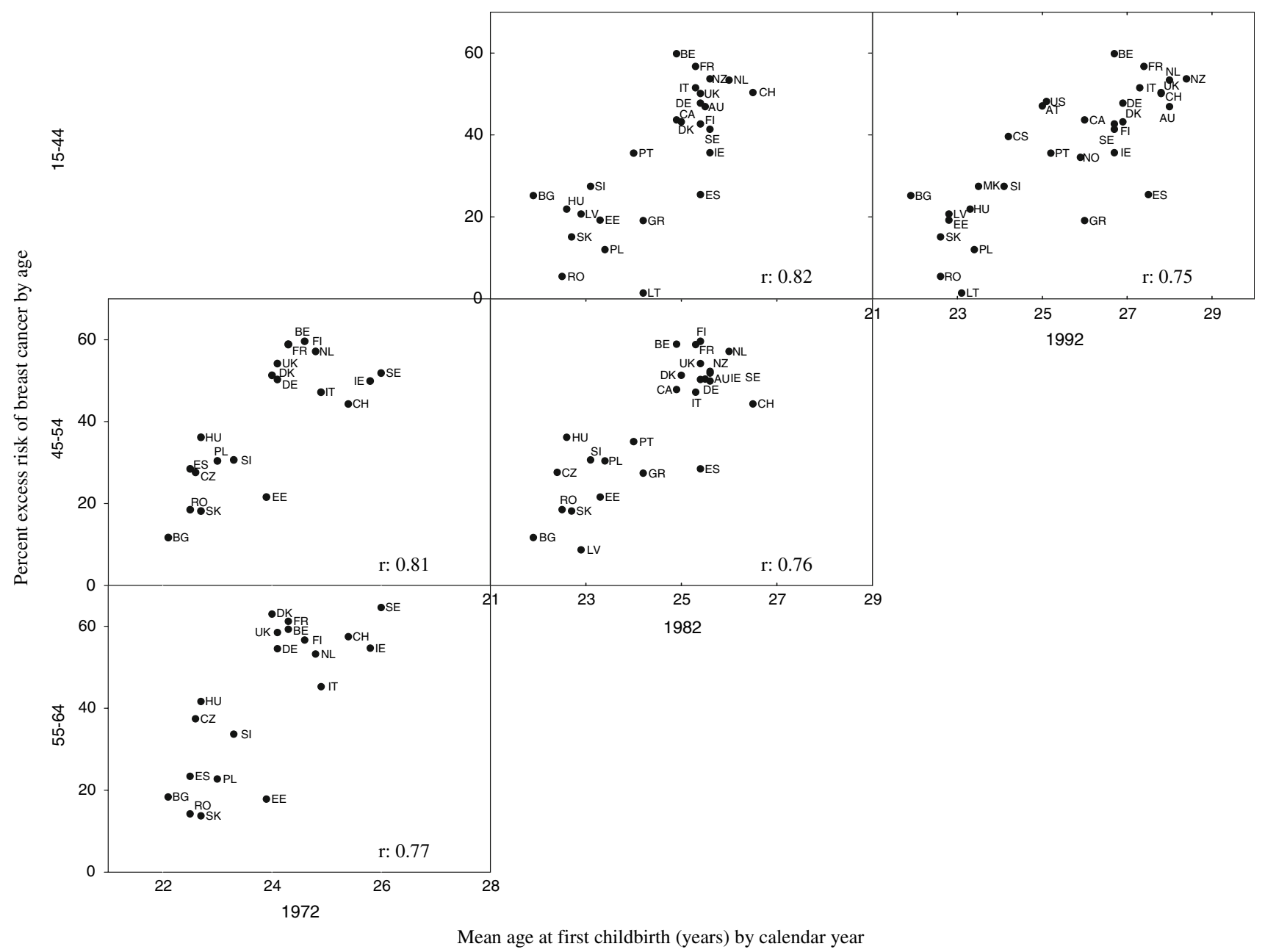

Fig. 1 Plot of mother's average age at first birth and the percent excess risk of breast cancer among women in 2002, by age groups and calendar years AU: Australia, AT: Austria, BE: Belgium, BG: Bulgaria, HR: Croatia, CA: Canada, CZ: Czech Republic, DK: Denmark, EE: Estonia, FI: Finland, FR: France, DE: Germany, GR: Greece, HU: Hungary, IE: Ireland, IT: Italy, LV: Latvia, LT:

observed rate. Hence, the relative excess in 2002 is supposed to be largely due to variations in external risk factors across populations, such as age at birth of first child, and hardly to genetic differences [13]. Though the latter may have played a interactive role, the prevalence of predisposing breast cancer genes is too low to explain these interpopulation differences [14]. Our results are consistent with previous studies [15-17] and supported by biological evidence of the role of pregnancy in the pathogenesis of breast cancer [18].

In affluent countries, the higher excess risk of breast cancer may be caused by practices of early detection and screening programs, especially among women over 50 [5]. In such populations, age at first birth also tends to be higher. However, increasing breast cancer rates have also been observed in countries without national screening
Lithuania, MK: Macedonia, NZ: New Zealand, NO: Norway, PL: Poland, PT: Portugal, RO: Romania, CS: Serbia and Montenegro, SK: Slovakia, SL: Slovenia, ES: Spain, SE: Sweden, CH: Switzerland, NL: The Netherlands, UK: United Kingdom and US: United States of America

programs (e.g. Czech republic, Slovenia, Slovakia, Estonia and Norway) [5]. Moreover, in countries where organized screening is present such as in the Netherlands and in Finland, increasing rates of breast cancer have been observed before the screening period [5]. Thus, it is unlikely that higher breast cancer rates in industrialized societies are entirely attributable to screening.

The excess of cases of breast cancer in 2002 reflects past exposure to multiple risk factors. Availability of comparable data on other risk factors is limited for most countries, and we were therefore unable to adjust for possible confounders, such as parity or duration of hormonal contraception use, which are also related to breast cancer risk [19]. Moreover as with any correlation study, observed correlations may be due to these other factors [20]. However, studies have shown that after correcting for other 
breast cancer risk factors such as oral contraceptive use and number of children, age at first birth remained an independent indicator of higher breast cancer risk among women who were older at birth of their first child [17, 19].

We correlated average age of mother at first birth to breast cancer risk, hence our finding might not sufficiently apply to the increasing proportion of childless women with an even higher breast cancer risk [21]. The proportion of women still childless at age 40 might therefore be an indicator for the proportion of nulliparous and be used in the analysis to adjust for it. However historical data for this indicator is limited and when available (e.g. in 2002), [22] we found a very high correlation with average age at first birth ( $r: 0.90$, data not shown). The observed correlation in this study thus partly reflects the risk of childless women; nations in which women were older at delivery of their first child also comprise a higher proportion of childless women and a higher excess breast cancer risk.

We found the largest increase in age at first birth in countries with the highest relative risk of breast cancer between 1982 and 2002, being 3-4 years in the UK, the Netherlands, France Spain and Australia. By contrast, average age at first birth in countries like Bulgaria, Slovakia, Lithuania, Latvia and Poland hardly changed between 1982 and 1992, but increased by an average of 2 years between 1992 and 2002. Overall, the trend in postponing children seems to be continuing [22]. Despite some flattening in the Netherlands, postponement of childbearing is likely to be resumed, and mean age at first birth is predicted to increase up to 33 years [23]. A further increase of breast cancer incidence might be the result.

We observed a marked relationship between average age at first birth in 1972, 1982, and 1992 and excess risk among women diagnosed in 2002 with breast cancer aged 55-64, 45-54 and 15-44. Most women diagnosed with breast cancer at age 45 to 54 in 2002 probably had their first child 20-30 years before 2002, thus mostly around 1980 . For age groups 15-44 and 55-64 years, year of first childbirth was mostly around 1990 and 1970, respectively. The correlation between RER in 2002 and age at first delivery is thus equally seen among pre-menopausal and post-menopausal breast cancer [16]. Furthermore, we observed the correlation to decrease with shorter time since exposure (age at first birth): the correlation between RER in 2002 for all age groups (15+) and mean age at first birth in 1972 was 0.83 , continuously decreasing to 0.61 in 2002 . Findings were similar across all age groups, suggesting a lag time of 20-30 years until variation in age at first birth is projected on the risk of breast cancer in the population.

What about the association between age at first birth in 1992 and 2002 and excess breast cancer risk in 2002? Most women who gave birth to their first child in 1992 or 2002 were too young to account for the association with breast cancer risk in 2002. However, risk factors for breast cancer are generally clustered more in countries with a high incidence of breast cancer [16]. For example; younger age at menarche (by 1.1 year) has been reported in countries with a high breast cancer risk, such as United States and Wales as opposed to Taiwan and Japan with a lower risk [16]. Similarly, lower parity and higher prevalence of nulliparity was observed in high breast cancer risk countries [16]. Furthermore, in countries with a higher risk of breast cancer higher body mass index was also observed, [16] possibly also reflecting the combination of a diet high in calories and lack of exercise. Finally, wider use of alcohol among women [24] and post-menopausal hormonal therapy $[25,26]$ are generally observed in more affluent regions, thus also in populations with a higher incidence of breast cancer. To summarize, older age at first child delivery probably is also a risk indicator of clustering of risk factors in western populations. This implies that a part of excess cases might be preventable by other means.

Basically, opportunities appear to be small of modifying some of the known risk factors for breast cancer, especially the timing of conceiving children. Delayed childbirth represents increasing educational opportunities and career choices for most women [22]. As a consequence, enhancing the potential for altering modifiable risk factors becomes even more important: minimizing alcohol intake [27], avoiding weight gain by the combination of a balanced diet and enough physical activity [28] and promoting breast-feeding [29] should, to a certain extent, reduce the risk of breast cancer. Finally, this study suggests age at first birth as a useful indicator for forecasting future incidence of breast cancer.

Acknowledgement We thank all national statistic institutes for their data input. Valuable comments were given by Mauricio Avendano, David Brewster, Jolanta Lissowska, Hélène Sancho-Garnier, Dimitrios Trichopoulos and Esther de Vries. The study was conducted within the Eurocadet project, financed by the European Commission (contract number: SP23-CT-2005-006528).

\section{References}

1. Familial breast cancer (2001) Collaborative reanalysis of individual data from 52 epidemiological studies including 58,209 women with breast cancer and 101,986 women without the disease. Lancet 358(9291):1389-1399

2. Colditz GA, Rosner B (2000) Cumulative risk of breast cancer to age 70 years according to risk factor status: data from the Nurses' Health Study. Am J Epidemiol 152(10):950-964

3. Ravdin PM, Cronin KA, Howlader N, Berg CD, Chlebowski RT, Feuer EJ, Edwards BK, Berry DA (2007) The decrease in breastcancer incidence in 2003 in the United States. N Engl J Med 356(16): 1670-1674

4. Dano H, Hansen KD, Jensen P, Petersen JH, Jacobsen R, Ewertz M, Lynge E (2004) Fertility pattern does not explain social gradient in breast cancer in denmark. Int J Cancer 111(3):451-456 
5. Botha JL, Bray F, Sankila R, Parkin DM (2003) Breast cancer incidence and mortality trends in 16 European countries. Eur J Cancer 39(12):1718-1729

6. Pisani P (2000): Avoidable Cancer in Europe: Estimating Etiologic Fractions. Final Report to the European Commission. In. Lyon, France: IARC

7. Layde PM, Webster LA, Baughman AL, Wingo PA, Rubin GL, Ory HW (1989) The independent associations of parity, age at first full term pregnancy, and duration of breastfeeding with the risk of breast cancer. Cancer and steroid hormone study group. J Clin Epidemiol 42(10):963-973

8. Eurostat [http://www.epp.eurostat.cec.eu.int/portal/page?_pageid= 1090,30070682,1090_33076576\&_dad=portal\&_schema=PORTAL]

9. Althuis MD, Dozier JM, Anderson WF, Devesa SS, Brinton LA (2005) Global trends in breast cancer incidence and mortality 1973-1997. Int J Epidemiol 34(2):405-412

10. Eurocadet: towards less cancer in Europe [http://www.euro cadet.org/]

11. Parkin DM, Bray F, Ferlay J, Pisani P (2005) Global cancer statistics, 2002. CA Cancer J Clin 55(2):74-108

12. SEER*Stat software, version 5.3.1. Surveillance Research Program. [http://www.seer.cancer.gov]

13. Soerjomataram I, de Vries E, Pukkala E, Coebergh JW (2006) Excess of cancers in Europe: A study of eleven major cancers amenable to lifestyle change. Int J Cancer 120(6):1336-1343

14. Narod SA (2006) Modifiers of risk of hereditary breast cancer. Oncogene 25(43):5832-5836

15. Pisani $P$ (1992) Breast cancer: geographic variation and risk factors. J Environ Pathol Toxicol Oncol 11(5-6):313-316

16. Pathak DR, Whittemore AS (1992) Combined effects of body size, parity, and menstrual events on breast cancer incidence in seven countries. Am J Epidemiol 135(2):153-168

17. Chie WC, Hsieh C, Newcomb PA, Longnecker MP, Mittendorf R, Greenberg ER, Clapp RW, Burke KP, Titus-Ernstoff L, Trentham-Dietz A et al (2000) Age at any full-term pregnancy and breast cancer risk. Am J Epidemiol 151(7):715-722

18. Russo J, Mailo D, Hu YF, Balogh G, Sheriff F, Russo IH (2005) Breast differentiation and its implication in cancer prevention. Clin Cancer Res 11(2 Pt 2):931s-936s

19. Breast cancer and hormonal contraceptives (1996) Collaborative reanalysis of individual data on 53297 women with breast cancer and 100239 women without breast cancer from 54 epidemiological studies. Collaborative group on hormonal factors in breast cancer. Lancet 347(9017):1713-1727
20. Morgenstern H (1982) Uses of ecologic analysis in epidemiologic research. Am J Public Health 72(12):1336-1344

21. Anderson WF, Matsuno RK, Sherman ME, Lissowska J, Gail MH, Brinton LA, Yang XR, Peplonska B, Chen BE, Rosenberg PS et al (2007) Estimating age-specific breast cancer risks: a descriptive tool to identify age interactions. Cancer Causes Control 18(4):439-447

22. Billari FC, Liefbroer AC, Philipov D (2006) The postponement of childbearing in Europe: Driving forces and implications. Vienna Yearbook of population Research 2006. 1-17

23. Goldstein JR (2006) How late can first births be postponed? Some illustrative population-level calculations. Vienna Yearbook of Population Research 153-165

24. Sieri S, Agudo A, Kesse E, Klipstein-Grobusch K, San-Jose B, Welch AA, Krogh V, Luben R, Allen N, Overvad K et al (2002) Patterns of alcohol consumption in 10 European countries participating in the European prospective investigation into cancer and nutrition (EPIC) project. Public Health Nutr 5(6B): $1287-1296$

25. Keating NL, Cleary PD, Rossi AS, Zaslavsky AM, Ayanian JZ (1999) Use of hormone replacement therapy by postmenopausal women in the United States. Ann Intern Med 130(7):545-553

26. Bernstein L, Allen M, Anton-Culver H, Deapen D, Horn-Ross PL, Peel D, Pinder R, Reynolds P, Sullivan-Halley J, West D et al (2002) High breast cancer incidence rates among California teachers: results from the California teachers study (United States). Cancer Causes Control 13(7):625-635

27. Hamajima N, Hirose K, Tajima K, Rohan T, Calle EE, Heath CW Jr, Coates RJ, Liff JM, Talamini R, Chantarakul N et al (2002) Alcohol, tobacco and breast cancer-collaborative reanalysis of individual data from 53 epidemiological studies, including 58,515 women with breast cancer and 95,067 women without the disease. Br J Cancer 87(11):1234-1245

28. Lahmann PH, Friedenreich C, Schuit AJ, Salvini S, Allen NE, Key TJ, Khaw KT, Bingham S, Peeters PH, Monninkhof E et al (2007) Physical activity and breast cancer risk: the European Prospective Investigation into Cancer and Nutrition. Cancer Epidemiol Biomarkers Prev 16(1):36-42

29. Shantakumar S, Terry MB, Teitelbaum SL, Britton JA, Millikan RC, Moorman PG, Neugut AI, Gammon MD (2007) Reproductive factors and breast cancer risk among older women. Breast Cancer Res Treat 102(3):365-374 